\title{
Siempre nos quedará París
}

\section{We'll always have Paris}

Rafael del Barco Carreras: Periodista

rafadelbarco@gmail.com

\section{CURRÍCULUM VITAE}

Periodista perteneciente a varios medios tanto escritos como online. También es autor de varios libros sobre temática actual

\section{RESUMEN}

La zona Euro ha acordado en París imprimir todos los euros necesarios. Los europeos, por ambición, metieron sus euros y créditos en la burbuja financieroinmobiliaria española. Los técnicos aseguran que España necesitará los próximos tres años unos 150.000 millones de euros anuales, sólo para pagar su deuda externa.

\section{PALABRAS CLAVE}

Eurozona - España - Burbuja Financiera

\section{ABSTRACT}

The Euro area has agreed in Paris to print all euros needed. Europeans, for ambition, put your Euros and credit bubble in the Spanish financial and real estate. Technicians 
say that Spain will need the next three years some 150,000 million per year just to pay its foreign debt.

\section{KEY WORDS}

Eurozone - Spain - Financial Bubble

\section{TEXTO}

La Eurozona acuerda en París imprimir todos los euros necesarios

20-10-08. El Congreso de los Diputados, sin oposición, planes, y con el control del Banco de España (inspector de los desmandados bancos y cajas, y perfecto conocedor de su mecánica por la Central de Riesgos), ratifica los dos decretos anticrisis del Consejo de Ministros. La gran salvación de todas las crisis se le negaba a Zapatero, y la solución se dio por si sola ante dos solapadas realidades: la crisis de los dueños mayoritarios de la máquina de imprimir billetes, y deberles tanto dinero que si no se emitían inundando el Sistema Financiero Español no cobraban. Así de sencillo. Francia y Alemania, además del problema provocado desde América arrastrando en dominó a toda la banca mundial, debían tragarse el sapo español. Solucionar el problema principal conllevaba la solución del secundario. Ya no valían créditos más caros al Estado Español avalando cualquier operación de sus bancos y cajas, debían incluir España en el reparto de billetes directamente. Si en EEUU detenían el descalabro con 700.000 millones de dólares, en Europa lo cifran en 2 billones de euros. Tres veces más. En pura demagogia, se podría afirmar que los americanos se cobraban el Plan Marshall bombardeando la banca europea con papelitos falsos. 
Los europeos, por ambición, metieron sus euros y créditos en la burbuja financieroinmobiliaria española, atraídos por el espejismo de las vacaciones y las bellas casitas vendidas a sus jubilados. Hitler quería España para granero, huerta y vacaciones, y sin tiros la conquistaron, ignorantes de la habilidad que para el tocomocho tenemos los mediterráneos. De que las casitas eran más caras que las de la Costa Azul, peor calidad, un nido de estafas, y sus vacaciones una orgía de alcohol, drogas y prostitutas ya hacía tiempo que tomaron conciencia. También se apercibieron de la "basura" en las hipotecas garantía de los créditos a las instituciones bancarias españolas, por lo que el BCE rechazó esa garantía. Las "subprime" españolas descubiertas ya antes del crak americano. Las "ninja" americanas una broma con las de la costa española. Aquí se vendían pisos desde insolventes a inexistentes, y se fabricaban operaciones crediticias de pura estafa para recolocarse a las instituciones financieras europeas. Una verdadera e inmensa Estafa Piramidal fabricada por cajas y bancos, que además de absorber gran parte del dinero de sus ahorradores se sobrepasaron en un $20 \%$, endeudándose con el exterior.

En mis tiempos de bancario, a endosar a los bancos efectos sin valor se le llamaba "colocar pelotas", "letras de colusión", sin operación comercial que las respaldara. Se giraban a 90 días y en el mejor de los casos se pagaban renovándose hasta el infinito, de lo contrario, estafa y "quiebra". Los activos de los bancos a reventar de "pelotas", causa de la debacle bancaria tras la muerte de Franco, solucionada con más billetaje, fusiones e inflación.

Es probable que la total cifra española alcance en los próximos tres años más del 30\% de euros a emitir, con representar un 14\% de la población de la Eurozona y un optimista $11 \%$ de su PIB, sumados construcción y turismo, sin incluir drogas y prostitución, girando actualmente en negro este sector más que el primer y segundo de los industriales, construcción y automóviles, y generando en valor añadido y liquidez mucho más que cualquier otra actividad económica. Los técnicos aseguran 
que España necesitará los próximos tres años unos 150.000 millones de euros anuales, sólo para pagar su deuda externa. Cantidad que de inicio se propone para el "arranque", para que el Sistema Español no se hunda, y las ventanillas sigan suministrando dinero. Pero si el español de a pie (con algo de posibles) duda de su Sistema Financiero acumulando euros o comprando oro, y los más pudientes, o los restos del quebrado sector de los financieros-inmobiliarios, que han acumulado dinero negro a patadas (del que se benefician los bufetes especializados), piensan en paraísos fiscales, se necesitarán cifras de puro vértigo. Un sistema crediticio en expansión, la burbuja financiera, crea con los billetes circulando, diez veces su valor en saldos pasivos y activos, dinero que los bancos deben por sus cuentas corrientes $u$ otras fórmulas de captación y que le deben sus acreedores o invertido en negocios. Es decir, siendo moderados, con 10 unidades-billetes circulando se crean cien, disponibles en cuentas, por lo que un pánico obliga a emitir el resto, los 90. La creación de Dinero Bancario. Total, el Corralito Argentino, y además la quiebra del Sistema porque los "activos", en teoría garantizando los créditos a precio expansivo, apenas tienen valor en recesión. El proceso alcanza el paroxismo en plena Globalización, con deudas internacionales multiplicando esa sencilla relación en un supuesto mercado cerrado más o menos autárquico. Solo España, necesitaría en plena estampida, casi los 2 billones de euros que se calculan para toda la Eurozona. La solución, imprimir billetes, no funcionaría ni instalando una impresora en cada red de ventanillas y cajeros.

Un pequeño detalle, la Presidenta del TSJC, advierte que la avalancha de asuntos mercantiles y administrativos (de los que surgirán penales) amenaza con colapsar los juzgados de Barcelona. Yo le contestaría, que no se preocupe, que de siempre los juzgados han estado colapsados a beneplácito y ganancia de los grandes bufetes que a voluntad juegan con ese colapso acortando y alargando los sumarios. Los grandes casos de la época del "pelotazo" (un entrenamiento de lo actual) de los 80 aún colean, ver www.lagrancorrupcion.com. Una pieza indispensable en toda corrupta crisis, la 
corrupción judicial, parte de su desarrollo e indispensable soporte ulterior para los poderosos. Su presidente de la Audiencia, José Luis Barrera Cogollos tiene amplia experiencia, iniciada en el Caso Consorcio de 1980-3. Presidenta y Presidente saben y palpan ya lo que se le viene encima a Barcelona, en definitiva un gran negocio para el sector de la abogacía. La ciudad con más licenciados en Derecho o abogados por m2 y habitante de Europa, unos 20.000. En sólo una semana me comunican de viejos amigos, ex amigos y ex socios, varias "suspensiones de pagos", quiebras, ahora "concurso de acreedores", por cifras modestas, de 3 a 60 millones de euros. Una suerte que la "corrupción" acabara conmigo librándome en la actualidad de esos problemas, y si me caen varias denuncias falsas, como después de escribir mi primer libro en 1994, la ineficacia judicial espero vaya a mi favor y no eleven esas denuncias del final de los grandes montones al principio.

Resumiendo, si la única solución a la Crisis, negada por Zapatero y sus comparsas, era emitir billetes e inyectarlos sin freno a un corrupto sector financiero, una vez solucionado el escollo de no tener a su disposición la máquina, se avecina, además del descalabro empresarial de la construcción, una más que galopante inflación y presión impositiva a través de la generalizada subida de precios que quien viva de un sueldo o de una triste pensión dispondrá a cada año que pase de menos de lo indispensable... y esos representan el $80 \%$ de la población. Los votantes. 